\title{
The Effect of Pre-Tension on Deformation Behaviour of Natural Fabric Reinforced Composite
}

\author{
Paulè BEKAMPIENĖ ${ }^{1,2}$ *, Jurgita DOMSKIENE் ${ }^{1}$, Anne ŠIRVAITIENE ${ }^{1}$ \\ ${ }^{1}$ Department of Clothing and Polymer Products Technology, Kaunas University of Technology, \\ Studentu 56, LT-51424 Kaunas, Lithuania \\ ${ }^{2}$ Lithuanian Textile Institute, Demokratu 53, LT-48485 Kaunas, Lithuania
}

Received 28 June 2010; accepted 08 January 2011

\begin{abstract}
In the fiber-reinforced composites industry together with the promotion of environmental friendly production, synthetic materials are attempted to be replaced by renewable, biodegradable and recyclable materials. The most important challenge is to improve strength and durability of these materials. Matrix that supports the fiber-reinforcement in composite generally is brittle and deformation causes fragmentation of the matrix. Pre-tension of reinforcement is a well-known method to increase tensile strength of woven material. The current study develops the idea to use pretension of woven fabric in order to improve quality and strength properties of the obtained composite. Natural (cotton fiber) and synthetic (glass fiber) woven fabrics were investigated. The pressure forming operation was carried out in order to study clamping imposed strain variation across the surface of woven fabric. The uniaxial tension test of singlelayer composite specimens with and without pre-tension was performed to study the effect of pre-tension on strength properties of composite. The results have shown that pre-tension imposed by clamping is an effective method to improve the quality of shaped composite parts (more smoothed contour is obtained) and to increase the strength properties of composite reinforced by woven natural fabric. After pre-tension the tensile strength at break increased in $12 \%$ in warp direction, in $58 \%$ in weft direction and in $39 \%$ in bias direction.

Keywords: fiber-reinforced composite, woven fabric, clamping, pre-tension, pressure forming, tensile properties.
\end{abstract}

\section{INTRODUCTION}

Advanced production in the field of fiber-reinforced composites (FRC) indicates trends of sustainable materials design. The development of ecology oriented ideas reflects not only in scientific research, but in strategies of enterprises as well. Together with the promotion of environmental friendly production and energy saving there is attempt to replace synthetic materials by renewable, biodegradable and recyclable natural materials.

Woven fabric is the most widely used textile structural reinforcement, since it provides excellent integrity and conformability during forming of composite parts with single $[1,2]$ and especially with double curvature (complex shape) [1-9]. However, mostly synthetic woven structures such as glass, carbon are used, because of their high strength to weight ratio. The most important challenge is to improve the strength and durability of natural materials. As a result, the successions of research works were conducted to investigate the various factors effect on the mechanical properties of FCR. Fiber content [10-13], processing [1-3] and treatment $[14-16]$ regimes, fiber-matrix compatibility $[3,17,18]$, composite manufacturing methods $[1,2,19]$ and other topics are discussed by researchers.

The matrix material that supports the FCR generally is brittle. It is relatively stiff or rigid polymer material that exhibits little or no plastic deformation. Applied stress tends to matrix fracture at low stress [20]. To avoid composite fracture reinforcement material in ideal case must be inelastic. Properties of above mentioned highly oriented synthetic fibers are close to inelastic. From the

\footnotetext{
*Corresponding author. Tel.: +370-673-60000; fax.: +370-37-353989. E-mail address: paule.bekampiene@gmail.com (P. Bekampienè)
}

range of natural fiber the higher properties are inherent for flax and ramie fibers. To improve the degree of molecular chain orientation in a fiber as well as the fiber orientation in a fabric the pre-tension can be applied.

Pre-tension is widely used method to increase tensile strength of material [18,21-25]. The low loading of warp yarn system before fabric weaving process is well known example of woven structures pre-tension. Pre-tension during weaving determines higher tensile characteristic values of the fabric loaded in warp direction. This is valid for non-impregnated and resin impregnated fabrics [26]. Precontraint ${ }^{\circledR}$ technology created by Ferrari ${ }^{\circledR}$ effectuates alongside pre-tension of warp and weft fiber systems during woven fabric coating process [27], which results higher dimensional stability and ability to resist loads, actual for tensioned structures design. Pre-tension also provides improved reinforcement effect during woven fabric-concrete structure forming, where the possibilities to replace synthetic fibers by natural are also considered $[18,21]$.

Moreover, pre-tension is often used during complex shape parts forming process. The pre-tension effects deformation properties of fabric and depends on clamping mode, part shape and fabric orientation.

The clamping fixture is applied to locate and hold a fabric in deformed state during manufacturing operations and the higher quality of formed parts is secured [28-32]. The most often clamping fixture with some hold-down pressure is proposed in order to avoid yarn damages when the limit of elastic deformation is overstepped [28 - 32].

The current study develops the idea to use pre-tension of woven fabric in order to improve quality and strength properties of natural (cotton fiber) and synthetic (glass 
fiber) woven fabrics composite. The pressure forming operation was carried out in order to study clamping imposed strain variation across the surface of woven fabric. The uniaxial tension test of single-layer composite specimens with or without pre-tension was performed to study the effect of pre-tension on strength properties of the composite.

\section{EXPERIMENTAL}

\subsection{Materials}

The composite was produced from glass fiber and cotton fabrics (Table 1) and unsaturated polyester resin. A methyl ethyl ketone peroxide initiator at concentration of $2.00 \mathrm{wt} \%$ was added to cure the resin.

Table 1. The main properties of composite reinforcement

\begin{tabular}{|l|c|c|c|}
\hline \multicolumn{2}{|c|}{ Characteristic } & \multicolumn{2}{c|}{ Woven reinforcement } \\
\hline \multicolumn{2}{|l|}{ Content $(100 \%)$} & E-glass & cotton \\
\hline \multicolumn{2}{|l|}{ Weave type } & plain & plain \\
\hline \multicolumn{2}{|l|}{ Area density, g/m ${ }^{2}$} & 80.00 & 137.00 \\
\hline \multicolumn{2}{|l|}{ Thickness, mm } & 0.11 & 0.32 \\
\hline \multirow{2}{*}{$\begin{array}{l}\text { Number of threads, } \\
\text { cm }^{-1}\end{array}$} & warp & 12 & 23 \\
\cline { 2 - 4 } & weft & 11 & 22 \\
\hline \multirow{2}{*}{$\begin{array}{l}\text { Linear density, } \\
\text { tex }\end{array}$} & warp & 34.09 & 30.00 \\
\cline { 2 - 4 } & weft & 33.67 & 27.45 \\
\hline
\end{tabular}

\subsection{Pressure forming}

Two different forming moulds were used to investigate the clamping effect on quality of formed part of the composite. The forming mould was composed of lower tool, upper tool and clamping fixture (blank-holder and clips) (Fig. 1). The upper tools have different spatial shape and quarter segments of them (Fig. 2) were used for the analysis. One-node tool I (area $-66215 \mathrm{~mm}^{2}$ ) (Fig. 2, a) has one hemi-sphere form spatial segment in the centre of plain. The four-node tool II $\left(61792 \mathrm{~mm}^{2}\right)$ (Fig. $\left.2, \mathrm{~b}\right)$ has four frustum cone spatial segments arranged in particular way that can be considered as the network of one-node tools. Both tools have different coefficients of complexity, which were calculated as the ratio of whole area to plain area of a tool. The coefficient of tool I complexity was 1.2 and tool II -1.05 .

During forming process, fabrics samples with printedon squares grid (length $10 \mathrm{~mm}$ ) were impregnated with resin, placed on the surface of the lower mould and fixed with blank-holder and clips. Such clamping method allows fabric to slip over the surface preventing fiber break-up when the certain load is reached. Then upper mould was pressed on the lower mould and kept in deformed state at room temperature until composite had completely cured.

The variation of strain (elongation $\varepsilon$ and shear angle $\gamma$ ) across the symmetric area of surface in formed part of composite (Fig. 2) was estimated by measuring the changes of squared grid. The variations of local elongation in warp $\varepsilon_{\mathrm{warp}(i)}$ and weft $\varepsilon_{\mathrm{weft}(i)}$ direction and local shear angle $\gamma_{(i)}$ were defined as:

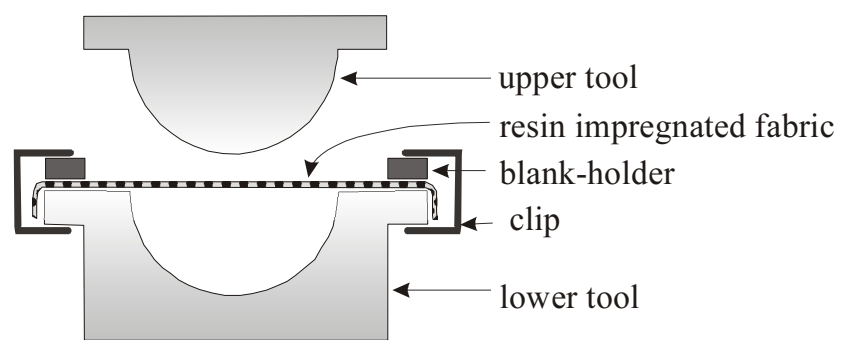

Fig. 1. The scheme of the mould I

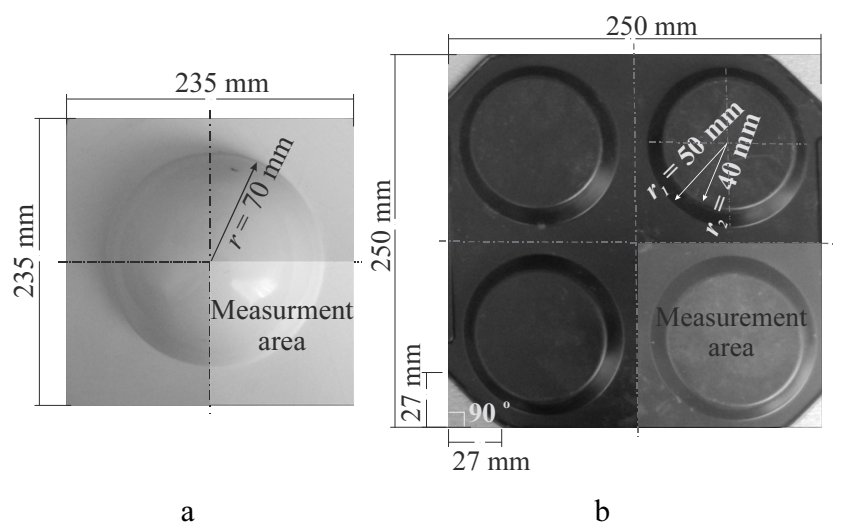

Fig. 2. The shape of upper forming tool: $\mathrm{a}$ - one-node I, $\mathrm{b}$ - fournode II

$\varepsilon_{\mathrm{warp} / \text { weft }(i)}=\Delta d_{\mathrm{warp} / \mathrm{weft}(i)} / d_{0} \times 100 \%$,

$\gamma_{(i)}=90-\theta_{(i)}$,

where $d_{0}$ is the original length of squared grid $(10 \mathrm{~mm})$, $\Delta d_{(i)}$ is the change of grind length in warp or weft direction and $\theta_{(i)}$ is the local angle between two yarns systems measured between parallel grid sides.

The measurements were taken manually using ruler (accuracy $\pm 0.5 \mathrm{~mm}$ ) and goniometer (accuracy $\pm 1^{\circ}$ ).

\subsection{Uniaxial tension of composite}

The single-layer samples with and without pre-tension were prepared to study the effect of pre-tension on tensile properties of the composite. The fabric samples of size $(60 \times 270) \mathrm{mm}^{2}$ oriented in warp, weft and bias directions were impregnated applying resin to one side of fabric until yarns were soaked. In the case of pre-tensioned samples $10 \%$ fabric elongation was ensured before impregnating by resin. Then samples were cured at room temperature. From each sample two rectangular specimens with operating area of $(20 \times 100) \mathrm{mm}^{2}$ were cut. The properties of obtained composite material are presented in Table 2. The fiber volume fraction of composite was calculated on the basis of final composite weight and initial weight of the fabric pieces.

Table 2. The main properties of composite material reinforced by different woven fabrics

\begin{tabular}{|l|c|c|}
\hline \multicolumn{1}{|c|}{ Characteristic } & \multicolumn{2}{c|}{ Composite } \\
\hline Woven reinforcement & E-glass & cotton \\
\hline Area density, $\mathrm{g} / \mathrm{m}^{2}$ & 291.16 & 424.60 \\
\hline Thickness, $\mathrm{mm}$ & 0.32 & 0.58 \\
\hline Fibre volume fraction, $\%$ & 27 & 32 \\
\hline
\end{tabular}


The uniaxial tension test was performed by universal tensile testing machine "Tinius Olsen" (load cell $-10 \mathrm{kN})$. The distance between grips was $100 \mathrm{~mm}$ and headway of upper clamp $-2 \mathrm{~mm} / \mathrm{min}$. 6 specimens for each test session were tested and tensile characteristics of the composite material were defined.

\section{RESULTS AND DISCUSSION}

\subsection{Pressure forming}

The comparison of unclamped and clamped shaping process has shown the improved quality of composite parts because less wrinkling failures were observed for clamped specimens due to the decreases of fabric amount per unit area of the tool (Fig. 3). To prevent fabric wrinkling by applying a suitable hold-down pressure is also proposed in other research works $[28,30]$. The more significant positive effect of pre-tension was observed in the case of cotton fabric and less wrinkling was observed during the obtained composite reinforced by cotton fabric spatial shape forming (Fig. 4). These results can be explained analysing the local deformations variation across the deformed fabric surface.

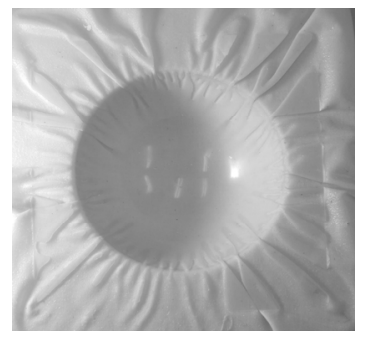

a

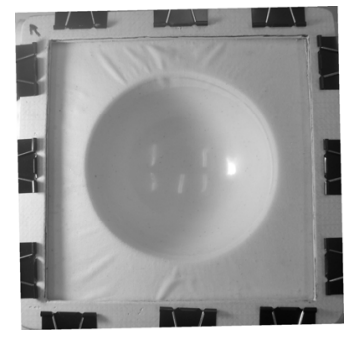

b
Fig. 3. The wrinkles arise in unclamped (a) and clamped (b) cotton fabric of one-node I composite part

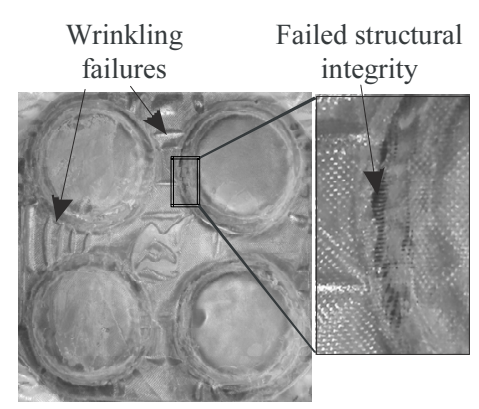

a

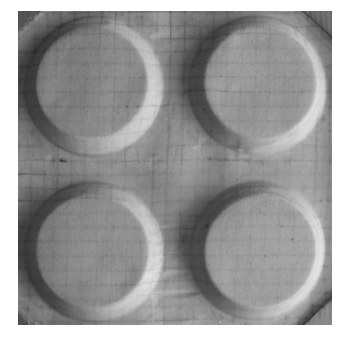

$\mathrm{b}$
Fig. 4. The view of clamped four-node II composite part reinforced with glass fiber (a) and cotton (b) fabrics

The results of local deformation variations in the one-node I part are presented in Fig. 5, a, and 5, b). It is clear that the main deformation mode in glass fiber fabric is shear (Fig. 5, a) and contraction (which is the negative elongation) and no significant variation of elongation were obtained. Maximum $\varepsilon_{\mathrm{weft}(i)}=(-15) \%-(-20) \%$ values were obtained due to the low glass fiber elasticity modulus. Therefore, the glass fiber fabric can detain the shape of the tool only due to shearing, i. e. yarns rotation over crossover points. The shear angle variance was observed across the all surface of the glass fiber fabric. The highest shear angle values (in the range of $30^{\circ}-40^{\circ}$ ) were reached at the intersection of plain and spatial segments of a tool (Fig. 5, a).

In the case of cotton fabric (Fig. 5, b) the changes in shear angle were observed only in the central part of plain segment and the highest shear angle values were in the same range as in glass fiber fabric. Though this fabric has reached significant elongation values in warp and weft directions (in the range of $15 \%-20 \%$ ) and it shows fabric ability to be shaped not only in bias direction, but in principal yarn directions as well. Consequently the amount of cotton fabric per unit area of the mould has decreased more significantly $\left(40600 \mathrm{~mm}^{2}\right)$ than in the case of glass fiber fabric $\left(44000 \mathrm{~mm}^{2}\right)$. This has determined the higher quality of the formed composite reinforced by cotton fabric part with less wrinkling failures.

During forming of four-node II part the same tendencies were observed; however, no significant shear deformations were obtained because of the low tool complexity (Fig. 6). However specific problem related with tool geometry was detected: during glass fiber fabric shaping (Fig. 6, a) the yarn sliding between neighbour nodes was prevented and wrinkles were formed (Fig. 4). The reason of these defects was the low elastic modulus of glass fiber fabric when during pressing the yarns integrity failed. Wrinkling was avoided during composite reinforced by cotton fabric forming due to the elastic behaviour inherent to this fiber type (Fig. 6, b). The amount of cotton fabric per unit area of the mould has decreased more significantly $\left(59600 \mathrm{~mm}^{2}\right)$ than in the case of a glass fiber fabric $\left(60600 \mathrm{~mm}^{2}\right)$.

\subsection{Uniaxial tension of composite}

According to the results presented in the previous section pre-tension of cotton fabric was applied in warp, weft and bias directions, while glass fiber fabric was pretensioned only in bias direction.

The uniaxial tension curves $(\sigma-\varepsilon)$ of composite specimens are presented in Fig. 7. The results when no pretension was applied have shown that in the case of composite reinforced with glass fiber fabric oriented in warp and weft directions the strength and yield points have coincided - the matrix and reinforcement fractioned simultaneously, whereas the specimen oriented in the bias direction have further elongated after yield due to the prime fragmentation of matrix. Similar behaviour has been shown by all composite specimens reinforced with cotton fabric (oriented in warp, weft and bias directions).

The study of pre-tension effect on the composite behaviour has clarified the positive effect of this process on the tensile properties. This corresponds well with results presented in other research papers [21,29]. The strength and yield points of pre-tensioned specimens have more coincided. Pre-tension significantly increases the tensile strength at break and decreases the elongation at break. Bias cotton fabric reinforced composite was an exception, because it has reached high value of elongation and it can be related to the insufficient pre-tension. After pre-tension of cotton fabric the tensile strength at break increased in $12 \%$ in warp direction, in $58 \%$ in weft direction and in $39 \%$ in bias direction. In the case of bias glass fiber fabric 

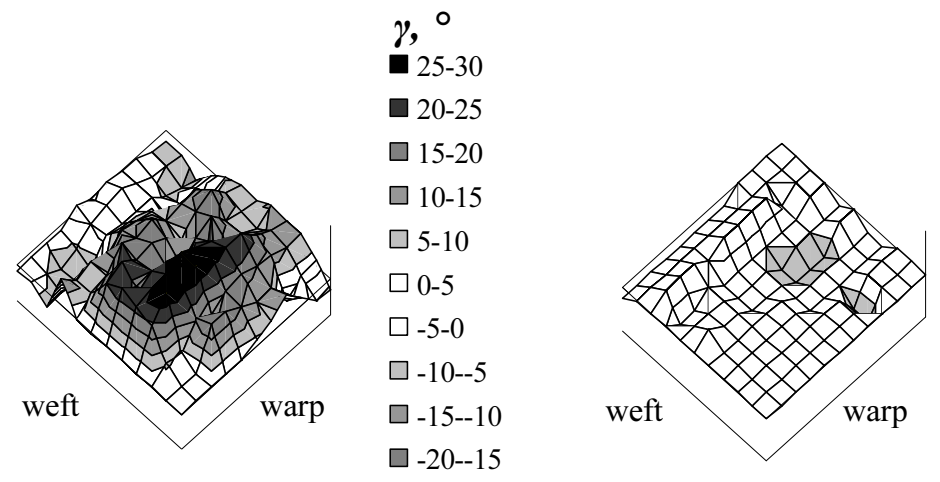

a

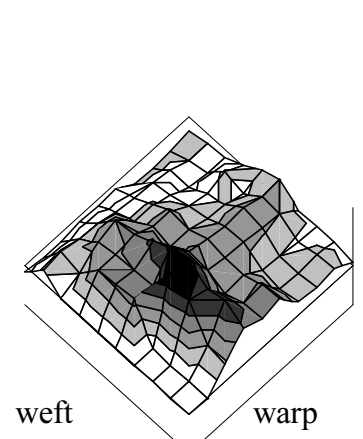

$\boldsymbol{\gamma}^{\circ} \stackrel{\circ}{ }$
$\square 25-30$
$\square 20-25$
$\square 15-20$
$\square 10-15$
$\square 5-10$
$\square 0-5$
$\square-5-0$
$\square-10--5$
$\square-15--10$
$\square-20--15$

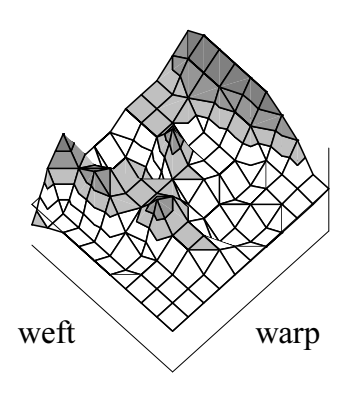

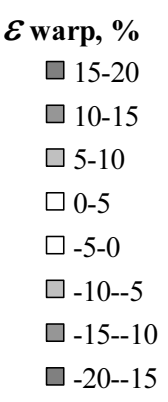

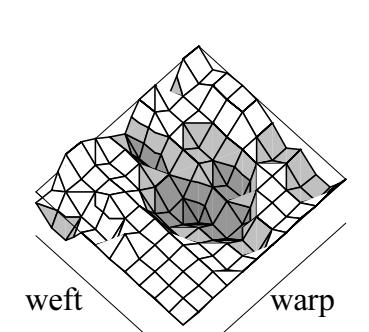

$\varepsilon$ weft, \%

$\square$ 15-20

$\square$ 10-15

$\square$ 5-10

$\square 0-5$

$\square-5-0$

$\square-10--5$

$\square-15--10$

$\square-20--15$

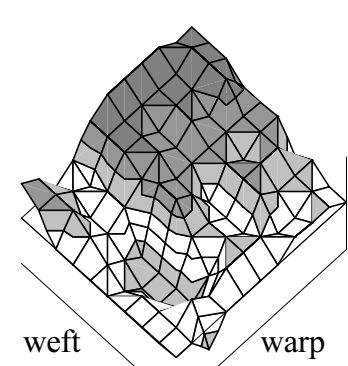

$\varepsilon$ weft, $\%$

$\square$ 15-20

$\square$ 10-15

$\square$ 5-10

$\square 0-5$

$\square-5-0$

$\square-10--5$

$\square-15--10$

$\square-20--15$

b

Fig. 5. Deformation variation across the surface of one-node I composite produced with glass fiber (a) and cotton (b) fabrics
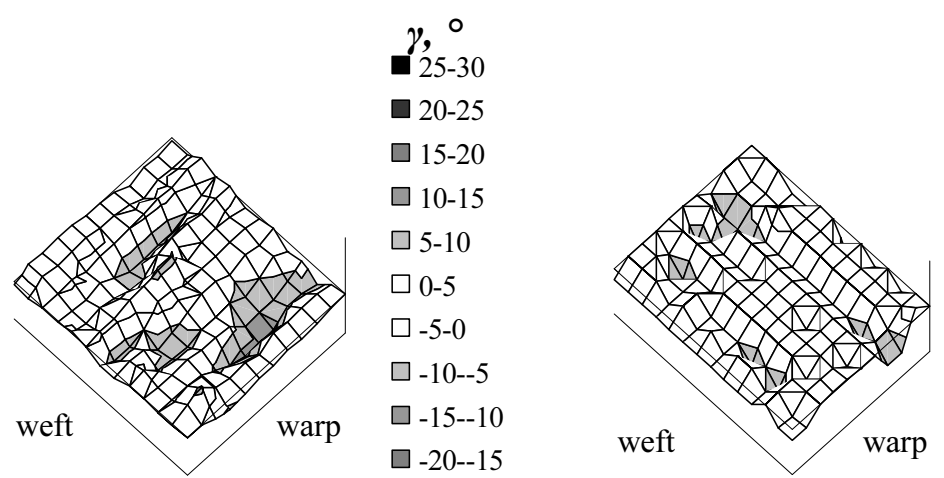

a

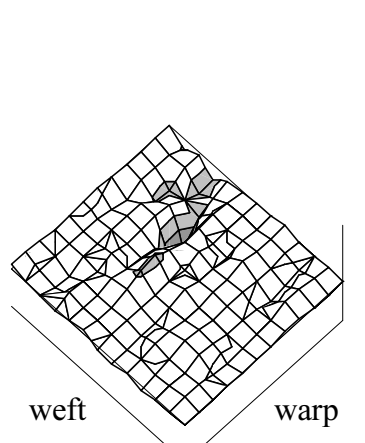

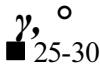
口20-25
$\square 15-20$
$\square 10-15$
$\square$ 5-10
$\square 0-5$
$\square-5-0$
$\square-10--5$
$\square$-15--10
$\square-20--15$

$\varepsilon$ warp, \%

ㅁ 15-20

$\square$ 10-15

$\square$ 5-10

$\square 0-5$

$\square-5-0$

$\square-10--5$

$\square-15--10$

$\square-20--15$

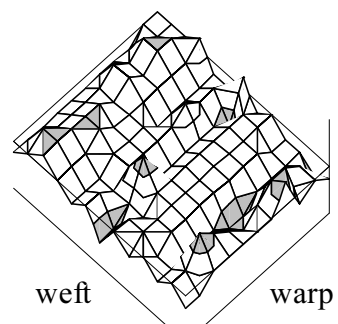

$\varepsilon$ weft, $\%$

$\square$ 15-20

$\square$ 10-15

$\square$ 5-10

$\square 0-5$

$\square-5-0$

$\square-10--5$

$\square-15--10$

-20--15
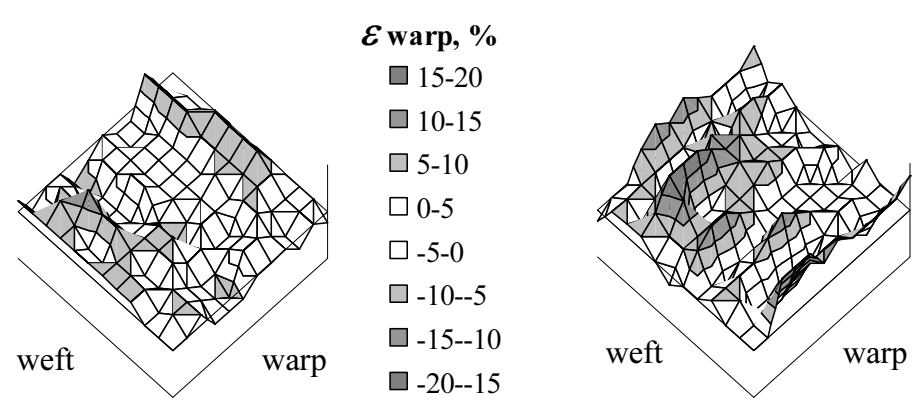

$\varepsilon$ weft, $\%$

$\square$ 15-20

$\square$ 10-15

$\square$ 5-10

$\square 0-5$

$\square-5-0$

$\square-10--5$

$\square-15--10$

$\square-20--15$

b

Fig. 6. Deformation variation across the surface of four-node II composite produced with glass fiber (a) and cotton (b) fabrics 

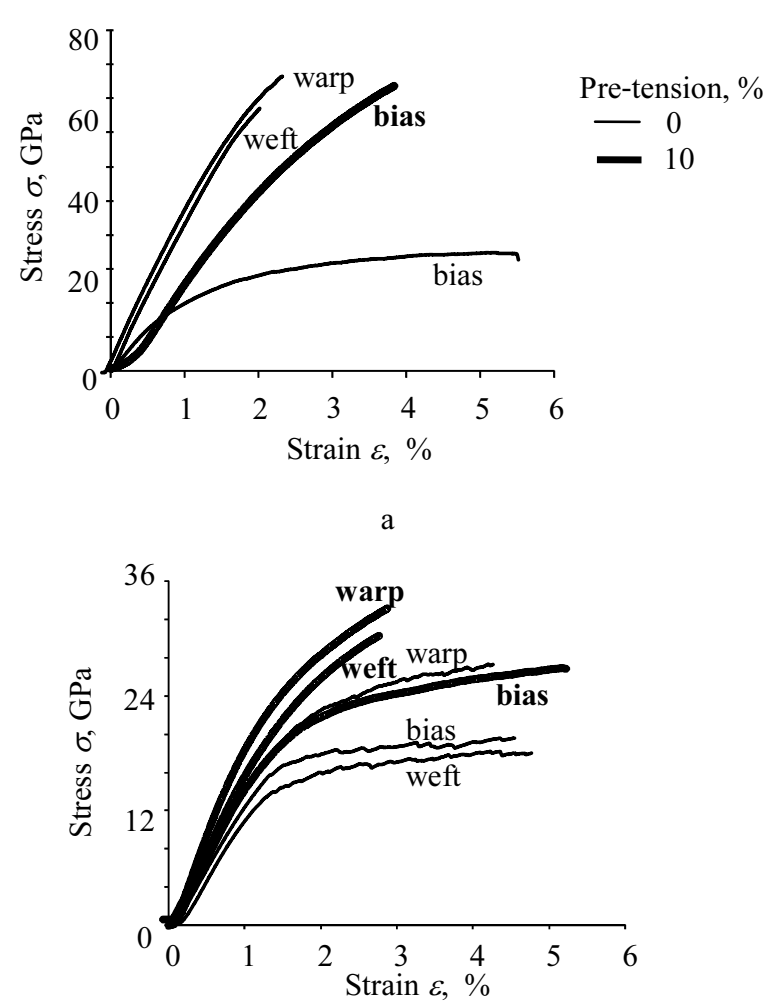

$\mathrm{b}$

Fig. 7. The tensile curves of composite material reinforced with glass fiber (a) and cotton (b) fabric

reinforced composite the tensile strength at break increased in $135 \%$.

Regardless to improved by pre-tension tensile characteristics of cotton fabric the lower tensile parameters were obtained for the composite reinforced with pretensioned cotton fabric. However, it must be highlighted that cotton is one of the weakest textile fiber.

\section{CONCLUSIONS}

In this work the effect of pre-tension imposed by clamping on quality of woven fabric reinforced composite part was studied and strain variation across the surface of woven cotton and glass fiber fabrics was measured.

The results have shown that pre-tension imposed by fabric clamping improves quality of shaped composite part significantly. Less wrinkling failures are obtained due to decrease of fabric amount per unit area of the tool. Cotton fabric covers the contour of the mould tool more tightly then glass fiber fabric. This is related to the ability of natural fabric not only to shear but also to elongate in principal yarn directions, while synthetic fabrics such as glass fiber can be deformed only through shearing and contraction.

The uniaxial tension test was carried out to estimate the effect of pre-tension on tensile properties of composite reinforced with woven fabric. The results have clarified the improved tensile characteristics of pre-tensioned composite specimens. After pre-tension of cotton fabric the composite tensile strength at break increased in $12 \%$ in warp direction, in $58 \%$ in weft direction and in $39 \%$ in bias direction.
This study shows that fabric pre-tension by appropriate clamping fixture could be the effective procedure to improve the quality and to increase the tension properties of composite reinforced with natural fabric.

\section{Acknowledgments}

The authors gratefully acknowledge the contributions from the specialists of the JSC "Danplastas".

\section{REFERENCES}

1. Goutianos, S., Peijs, T., Nystrom, B., Skrifvars, M. Textile Reinforcements Based on Aligned Flax Fibres for Structural Composites. Composites Innovation 2007 Improved Sustainability and Environmental Performance, Barcelona (ES), 4-5 Oct 2007.

2. Goutianos, S, Peijs, T, Nystrom,B, Skrifvars, M. Development of Flax Fibre Based Textile Reinforcements for Composite Applications Applied Composite Materials 13 2006: pp. 199-215.

3. Arzondo, L. M., Perez, C. J. Use of Preimpregnated Sisal Yarn in Woven Reinforced Polypropylene Sheets: Thermoformability and Mechanical Properties Polymer Engineering and Science 45 (7) 2005: pp. 976-983.

4. Molnar, P., Ogale, A., Lahr, R., Mitschlang, P. Influence of Drapability by Using Stitching Technology to Reduce Fabric Deformation and Shear during Thermoforming. Composite Science and Technology 67 (15-16) 2007: pp. 3386-3393.

5. Cherouat, A., Billoët, J. L. Mechanical and Numerical Modelling of Composite Manufacturing Processes Deepdrawing and Laying-up of Thin Pre-impregnated Woven Fabrics Journal of Materials Processing Technology 118 (1-3) 2001: pp. 460-471.

6. Juodsnukytė, D., Daukantienė, V., Gutauskas, M. Investigating the Implications of Static and Dynamic Loading in High-performance Fabrics for Outdoor Clothing International Journal of Clothing Science and Technology 20 (1) 2008: pp.7-14.

7. Naujokaitytè, L., Strazdienè, E., Titas, R. The Effect of Temporary Stiffeners Concentration upon Bending Properties of Fabrics Materials Science (Medžiagotyra) 11 (3) 2005: pp. $283-287$.

8. Dobilaitė, V., Jucienė, M. Evaluation of Seam Pucker Using Shape Parameters Materials Science (Medžiagotyra) 16 (2) 2010: pp. $154-158$.

9. Bekampienè, P., Domskienè, J. Influence of Stitching Pattern on Deformation Behaviour of Woven Fabric during Forming Materials Science (Medžiagotyra) 16 (3) 2010: pp. $226-230$.

10. Pothan, L. A., Potschke, P., Habler, R., Sabu, T. The Static and Dynamic Mechanical Properties of Banana and Glass Fiber Woven Fabric-Reinforced Polyester Composite Journal of Composite Materials 39 (11) 2005: pp. $1007-1025$.

11. Sabeel, A. S., Vijayarangan, A. K. Low Velocity Impact Damage Characterization of Woven Jute - Glass Fabric Reinforced Isothalic Polyester Hybrid Composites Journal of Reinforced Plastics and Composites 26 (10) 2007: pp. 959-976.

12. Paiva Junior, C. Z., de Carvalho, L. H., Fonseca, V. M., Monteiro, S. N., d'Almeida, J. R. M. Analysis of the Tensile Strength of Polyester/Hybrid Ramie-Cotton Fabric Composites Polymer Testing 23 2004: pp. 131-135. 
13. Akhbari, M., Shokrieh, M., Nosraty, H. A Study on Buckling Behavior of Composite Sheets Reinforced by Hybrid Woven Fabrics Transactions of the Canadian Society for Mechanical Engineering 32 (1) 2008: pp. $81-90$.

14. Xu, W., Li, Y. Cotton Fabric Strength Loss from Treatment with Polycarboxylic Acids for Durable Press Performance Textile Research Journal 70 (11) 2000: pp. 957-961.

15. Van de Weyenberg, I., Truong, T. Ch., Vangrimde, B., Verpoest, I. Improving the Properties of UD Flax Fibre Reinforced Composites by Applying an Alkaline Fibre Treatment Composite Part A 37 2006: pp. 1368-1376.

16. Baley, Ch., Busnel, F., Grohens, Y., Sire, O. Influence of Chemical Treatments on Surface Properties and Adhesion Flax Fiber-polyester Resin Composites Part A 37 2006: pp. $1626-1637$.

17. Arzondo, L. M., Vazquez, A., Carella, J. M., Pastor, J.M. A Low-cost, Low-fiber-breakage, Injection Molding Process for Long Sisal Fiber Reinforced Polypropylene Polymer Engineering and Science 44 (9) 2004: pp. 1766-1772.

18. Mohanty, A. K., Misra, M., Drzal, L. T. Sustainable BioComposites from Renewable Resources: Opportunities and Challenges in the Green Materials World Journal of Polymers and the Environment 10 (1/2) 2002: pp. 19-26.

19. Van de Velde, K., Kiekens, P. Thermoplastic Pultrusion of Natural Fibre Reinforced Composites Composite Structures 54 2001: pp. 355-360.

20. International Patent Pub. No. WO/2006/143030 Huang, B., Gale, D. C. Method of Fabricating an Implantable Medical Device to Reduce Change of Late Inflammatory Response.

21. Reinhardt, H. W., Krüger, M., Große, Ch. U. Concrete Prestressed with Textile Fabric Journal of Advanced Concrete Technology 1 (3) 2003: pp. 231-239.

22. Chena, Q., Ringleba, S. I., Manducab, A., Ehmanb, R. L., An, K-N. Differential Effects of Pre-tension on Shear Wave Propagation in Elastic Media with Different Boundary Conditions as Measured by Magnetic Resonance Elastography and Finite Element Modelling Journal of Biomechanics 39 (8) 2006: pp. 1428-1434.
23. Grubb, D. T., Ji, G. Molecular Chain Orientation in Supercontracted and Re-extended Spider Silk International Journal of Biological Macromolecules $24(2-3) \quad$ 1999: pp. $203-210$.

24. Jun, Ch., Ling-Fang, W., Wen-Xiang, Y., Wei-Lin, X. Effect of Filament Prie-tension on Performance of Wool/Polyester Embedded Composite Yarn Shanghai Textile Science and Technology 37 (11) 2009.

25. Burguenoa, R., Quagliataa, M. J., Mohantyb, A. K., Mehta, G., Drzald, L. T., Misra, M. Hybrid Biofiber-based Composites for Structural Cellular Plates Composites Part A 36 2005: pp. 581-593.

26. Xiong, J. J., Shenoi, R. A., Gao, J. An Analytical Model to Predict Residual Thermal Stress in 2D Orthogonal Plain Weave Fabric Composites International Journal of Solids and Structures 46 2009: pp. 1872-1883.

27. Moncrieff, E. Systems for Lightweight Structure Design: the State-of-the-Art and Current Developments Textile Composites and Inflatable Structures ISSN 1871-3033 3 2006: pp. $17-28$.

28. Lee, J. S., Hong, S. J., Yu, W. R., Kang, T. J. The Effect of Blank Holder Force on the Stamp Forming Behaviour of Non-crimp Fabric with a Chain Stitch Composite Science and Technology 67 2007: pp. 357-366.

29. Onal, L., Adanur, S. Optimization of Compression Molding Process in Laminated Woven Composites Journal of Reinforced Plastics and Composites 24 (7) 2005: pp. $775-780$.

30. Hou, M. Stamp Forming of Fabric-Reinforced Thermoplastic Composites Polymer Composites 17 (4) 1996: pp. 596-603.

31. Hamila, N., Boisse, Ph. Simulation of Textile Composite Reinforcement Draping Using a New Semi-discrete Three Node Finite Element Composite Part B 39 2008: pp. $999-1010$.

32. Bekampiene, P., Domskiene, J. Experimental Analysis of the Influence of Stress Concentrators on the Buckling of Woven Materials under Uniaxial Tension International Journal of Material Forming 3 2010: DOI: 10.1007/s12289-010-0744-x. 